\title{
Comparison of oxygen transfer efficiency using new types of baffle blocks
}

1 Mahmut Aydoğdu $\mathrm{PhD}$

Lecturer, Department of Construction, Darende Bekir llıcak Vocational School, Malatya Turgut Özal University, Malatya, Turkey
2 O. Faruk Dursun PhD

Associate Professor, Inonu University, Department of Civil Engineering, Battalgazi, Malatya, Turkey (corresponding author: ofdursun@gmail.com)
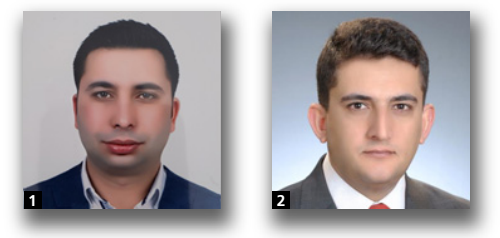

Oxygen is needed in water to maintain the natural ecological balance and the health of organisms. The amount of dissolved oxygen (DO) in water can be increased naturally in different ways. In particular, some hydraulic structures are designed so reoxygenation of water occurs spontaneously over a short distance and in a short time. Baffled chutes are designed to dissipate the energy of flow in irrigation systems, wastewater systems and stormwater systems. Staggered baffle blocks placed in a chute channel not only dissipate the energy of the water but also allow free oxygen transition between the water-air surface by means of hydraulic jumps. While water flows over, between and around the blocks, air bubbles are entrained into the water. The entrained air bubbles in the flow start to dissolve within the chute and the DO concentration in the water thus increases. In this study, the amount of DO was determined for baffle blocks with six different geometric shapes, different flow discharges and angle variations $\left(10^{\circ} \leq \alpha \leq 56^{\circ}\right)$. The oxygen transfer efficiency of the new baffle blocks designed in this study was found to be very effective. Different block types were found to have greater oxygen transfer efficiency for chutes with different slopes.

\section{Notation}

$C_{\mathrm{d}} \quad$ downstream D0 concentration

$C_{\mathrm{s}} \quad$ supersaturated DO concentration

$C_{\mathrm{u}} \quad$ upstream D0 concentration

$d_{\mathrm{c}} \quad$ critical depth

E

$E_{20}$

$E_{T}$

$\mathrm{Fr}$

$f_{T}$

g

$H$

$P$

$P_{\mathrm{w}}$

$Q$

$q$

$\operatorname{Re}$

$r_{15}$

$r_{T}$ height of block oxygen transfer efficiency (aeration efficiency)

oxygen transfer efficiency at reference temperature $\left(20^{\circ} \mathrm{C}\right)$

$$
\text { oxygen transfer efficiency at temperature } T
$$

Froude number temperature correction coefficient gravitational acceleration atmospheric pressure vapour pressure flow rate unit flow Reynolds number oxygen deficiency coefficient reference oxygen deficiency coefficient at $15^{\circ} \mathrm{C}$ oxygen deficiency coefficient at temperature $T$ slope of chute channel step height temperature water temperature critical velocity

$\begin{array}{ll}W & \text { inlet width of baffled chute } \\ \alpha & \text { chute angle } \\ \mu & \text { dynamic viscosity } \\ \rho & \text { density } \\ \sigma & \text { surface tension }\end{array}$

\section{Introduction}

In the daily changing world, fresh water has great importance for all living creatures. Among the parameters used to determine water quality, the amount of dissolved oxygen (DO) stands out. Polluted water can be aerated automatically to increase its oxygen content by making it through a long channel and there are many studies in the literature on protecting and increasing the quality and oxygen content of water in natural ways.

Gameson (1957) and Gameson et al. (1958) were the first to report a study on the natural oxygen transfer effect in water. They investigated the change in DO concentration in water as a result of different hydraulic structures in many rivers, grouping these structures as free-falling weirs, stepped weirs, gate weirs, sloped channels and mills. They measured the DO at the inlet and outlet of the hydraulic structures and proposed equations to calculate the oxygen transfer efficiency of the flow. 
Markofsky and Kobus (1978) defined the transport of oxygen from air into water in three stages - the entry of air into water, the transport of air through the aeration zone and the dissolution of oxygen in air bubbles into the water. The last step determines the water quality. An increase in water pollution means a decrease in the DO percentage in the water. The variation in flow characteristics with more air entry in high-slope channels was researched by Wood (1991). Kobus (1991) classified the hydrodynamic factors that provide natural oxygenation according to their occurrence over long and short distances. The hydrodynamic factors that provide natural oxygenation over short distances were defined as the height of the hydraulic jump and the water drop height, while those that provide natural oxygenation over long distances were grouped as free-surface flows that run through highly inclined and stepped channels. Watson et al. (1998) found that effective natural oxygenation was not provided in high-slope channels in their study.

The properties of hydraulic structures used for oxygen transfer to water have also been investigated. As an indirect purpose of hydraulic structures, to increase the oxygen concentration in water, hydraulic jump pools, dropping water from higher elevations, passing the water current through a rough or stepped channel or adding baffle blocks to the channel have been proposed (Gulliver and Rindels, 1993; Kherbache et al., 2017; Wu et al., 2013). Even if the contact time with water is short, these structures can raise the DO content of the water to the desired level in a short time. Such investments are thus essential to protect biological diversity and natural ecosystems. Generally, the process of treating polluted water is very complex because the oxygen transfer mechanism is changed in each hydraulic structure. The oxygen transfer mechanism has thus been tested by many researchers for a wide variety of hydraulic structures (Baylar et al., 2010; Chu et al., 2014; Essery et al., 1978; Felder and Chanson, 2009; Gulliver et al., 1997, 1998; Gulliver and Rindels, 1993; Tebbutt, 1972; Zhang, 2017; Zhang and Chanson, 2017).

Toombes and Chanson (2005) focused on developing measurement and prediction techniques for oxygen transfer in hydraulic structures in order to protect and improve water quality. They showed that $30 \%$ oxygen transfer efficiency was obtained for a structure with 12 steps and a low slope. Bung and Schlenkhoff (2010) conducted DO measurements in stepped spillways. Küçükali and Çokgör (2011) carried out systematic experiments on the classical hydraulic jump and found a strong relationship between the amount of DO and the energy dissipation rate. They also proposed a formula to estimate the hydraulic jump as a function of oxygen transfer efficiency, loss of head and flow rate through unit width. Wuthrich and Chanson (2015) examined the aeration performance of gabion stepped spillways.

Energy dissipaters are an important part of hydraulic structures and are also widely used for oxygen transfer efficiency
(Baylar and Emiroglu, 2004; Boes and Hager, 2003; Felder et al., 2019; Luna-Bahena et al., 2018; Medhi et al., 2019; Terrier et al., 2016). Staggered baffle blocks placed in a chute channel or in cascades not only dissipate the energy of the water but also allow free oxygen transition between the waterair surface through a hydraulic jump. While the water flows over the blocks, between the blocks and around the blocks, air bubbles are entrained in the water, thus increasing the DO content in the water. This situation is very valuable for both aquatic life and the quality of water for use by people. Kaya and Emiroglu (2010) noted a strong link between energy dissipation and oxygen transfer efficiency. They examined the oxygen yield using stepped, wedge, trapezoidal and T-shaped blocks and developed an empirical formula. Ashour et al. (2014) examined 14 types of curved blocks to increase the DO level and quality of irrigation water. Raikar and Kamatagi (2015) examined the effect of two different weir types and hydraulic jumps on oxygen transfer efficiency: the oxygen transfer efficiency of the triangular weir was found to be $19.48 \%$, while that of the rectangular weir was $10.12 \%$. In addition, it was experimentally proven that the weirs were more effective for oxygen transfer efficiency than the hydraulic jumps. Using five different algorithms, Gerger et al. (2017) calculated the oxygen transfer efficiency of blocks placed in a channel in a staggered manner.

Despite the importance of aeration of water, over-oxygenation of water by hydraulic structures can sometimes be harmful for aquatic life. If the level of oxygen in the water exceeds the supersaturation value, especially downstream of high dams, this can lead to gas bubble disease in fish or even death (Qu et al., 2011). Many studies have been performed to determine, model or estimate water quality parameters and gas transfer properties in rivers and streams (Wang et al., 2019; Wang and Zhang, 2020). Wang et al. (2021) investigated the variations in air-water gas transfer velocity $\left(K_{L}\right)$ across 35 streams and rivers. They found that the main source of $K_{L}$ variation shifted from bottom friction to other factors with an increase in stream size.

In the study reported in this paper, DO concentration was investigated using parameters related to six baffle blocks with different geometric shapes, unit flows and chute angles $\left(10^{\circ} \leq \alpha \leq 56^{\circ}\right)$. Numerous studies have been conducted about aeration in inclined canals. In this study, it was considered that new and different block geometries that cause more intense turbulence in water will have positive effects on aeration. This study was the first time these block types have been produced and tested. The use of blocks with higher aeration efficiency will provide the desired aeration capacity, even in shorter chute structures, which will contribute to an improvement in environmental conditions. The oxygenation performance of the six different types of baffle blocks was derived and the oxygen transfer efficiency of the channel without blocks was also determined. 


\section{Oxygen transfer process}

As already mentioned, an important parameter for determining water quality is the amount of DO in the water, which depends on the water temperature, the available oxygen content and the pollution in the water. When a liquid medium meets a gas medium, there is a gas molecule transition from liquid to gas or from gas to liquid. This situation continues until a state of fully developed flow occurs. In the condition of fully developed flow, the gas concentration in the liquid is saturated. Fick's law is related to the self-aeration of water. Accordingly, diffusion occurs along an air-water interface.

Gameson (1957) proposed that the aeration performance of a flow can be calculated as:

1. $E=1-\frac{1}{r}=\frac{C_{\mathrm{d}}-C_{\mathrm{u}}}{C_{\mathrm{s}}-C_{\mathrm{u}}}$

where $E$ is the oxygen transfer efficiency (aeration efficiency) coefficient, $r$ is the oxygen deficiency coefficient and $C_{\mathrm{u}}$ and $C_{\mathrm{d}}$ are, respectively, the upstream and downstream DO concentrations. $E$ usually ranges from $0-1: E=0$ indicates no aeration in the environment and $E=1$ indicates that the water is completely saturated with oxygen at the hydraulic structure outlet. A value of $E>1$ indicates that the downstream water has reached supersaturation $\left(C_{\mathrm{d}}>C_{\mathrm{s}}\right)\left(C_{d}>C_{s}\right)$. The values of $C_{\mathrm{u}}$ and $C_{\mathrm{d}}$ are measured experimentally. Taking into account atmospheric pressure, temperature and vapour pressure, the value of $C_{\mathrm{s}}$ can be determined as:

2. $C_{s}=\frac{(510.2-0.45 T)\left(P-P_{\mathrm{w}}\right)}{T+35}$

where $T$ is temperature, $P$ is atmospheric pressure and $P_{\mathrm{w}}$ is vapour pressure. A variation in the temperature of the fluid changes many of its properties. In particular, the specific mass, viscosity, surface tension and mass transfer coefficient of the fluid and the saturation value of the gas in the fluid change depending on temperature. This directly affects oxygen-water transfer. Thus, to compare studies about natural aeration, the coefficients $E$ and $r$ must be converted into standard temperature values. Generally, the reference water temperature is $20^{\circ} \mathrm{C}$.

In experiments on weirs, Gameson et al. (1958) found that the efficiency of aeration increased with an increase in the water temperature. They thus proved that the mass transfer coefficient increases with an increase in temperature. They proposed the equation:

3. $r_{15}=1+\frac{r_{T}-1}{1+0.027\left(T_{\mathrm{w}}-15\right)}$ where $r_{15}$ is the reference oxygen deficiency coefficient (at $\left.15^{\circ} \mathrm{C}\right), r_{T}$ is the oxygen deficiency coefficient at $T^{\circ} \mathrm{C}$ temperature in the working environment and $T_{\mathrm{w}}$ is the water temperature in the environment where the test is carried out. Gulliver et al. (1990) proposed the correlation:

\section{4. $\quad 1-E_{20}=\left(1-E_{T}\right)^{1 / f_{T}}$}

in which $E_{20}$ is the oxygen transfer efficiency (aeration efficiency) at the reference temperature of $20^{\circ} \mathrm{C}$ and $f_{T}$ is a temperature correction coefficient. The solution of Equation 4 is:

5. $f_{T}=\left(\frac{T+273}{T_{i}+273}\right)^{1 / 2}\left(\frac{\mu_{i}}{\mu}\right)^{3 / 4}\left(\frac{\sigma_{i}}{\sigma}\right)^{3 / 5}\left(\frac{\rho_{i}}{\rho}\right)^{17 / 20}$

where $\mu$ is the dynamic viscosity, $\rho$ is the density, $\sigma$ is the surface tension and the index $i$ indicates the fluid property at the reference temperature. Solving Equation 5 for a reference temperature of $20^{\circ} \mathrm{C}$ yields:

6. $f_{T}=1+0.02103\left(T_{\mathrm{w}}-20\right)+8.261 \times 10^{-5}\left(T_{\mathrm{w}}-20\right)^{2}$

\section{Experimental facility and instrumentation}

The tests were carried out in the Civil Engineering Hydraulics Laboratory of Inonu University, Malatya, Turkey. The experiments involved a chute channel $(0.4 \mathrm{~m}$ wide, $0.6 \mathrm{~m}$ deep and $4 \mathrm{~m}$ long) with an adjustable slope and into which blocks could be placed, a tank that could be moved vertically and pipe fittings to transfer water into the reservoir. The maximum flow rate was $75 \times 10^{-3} \mathrm{~m}^{2} / \mathrm{s}$. The side faces of the channel were made of glass and the base was made of sheet metal. A $15 \mathrm{~kW}$ centrifugal pump was used for water recirculation. A storage tank was used to mix chemicals to ensure that the DO in the water was zero. The water was pumped from the chemical mixing tank (storage tank) through a headbox (stilling tank), as shown in Figure 1. A grid was used to facilitate flow smoothening and reduce flow irregularities. An ogee crest was installed at the entrance of the test channel to provide uniform upstream flow. Flow conveyed from the chute was directed through the downstream channel. All the tests were performed in the per unit flow rate range of $12.5 \times 10^{-3} \mathrm{~m}^{2} / \mathrm{s}$ to $75 \times 10^{-3} \mathrm{~m}^{2} / \mathrm{s}$. An Arkon electromagnetic flowmeter with an accuracy of $\pm 0.01 \mathrm{l} / \mathrm{s}$ was used for flow measurements.

Six different baffle blocks were tested. As shown in Figure 2(a), four of the blocks had height $\times$ width $\times$ depth dimensions of $50 \times 50 \times 50 \mathrm{~mm}$ (type 1 , type 4 , type 5 and type 6 ) and the other two types had dimensions of $50 \times 100 \times 50 \mathrm{~mm}$ (type 2 and type 3). The flow direction (FD) in the system is also shown in Figure 2. All the blocks were made of wood, with a special yacht varnish applied to protect the blocks from water 

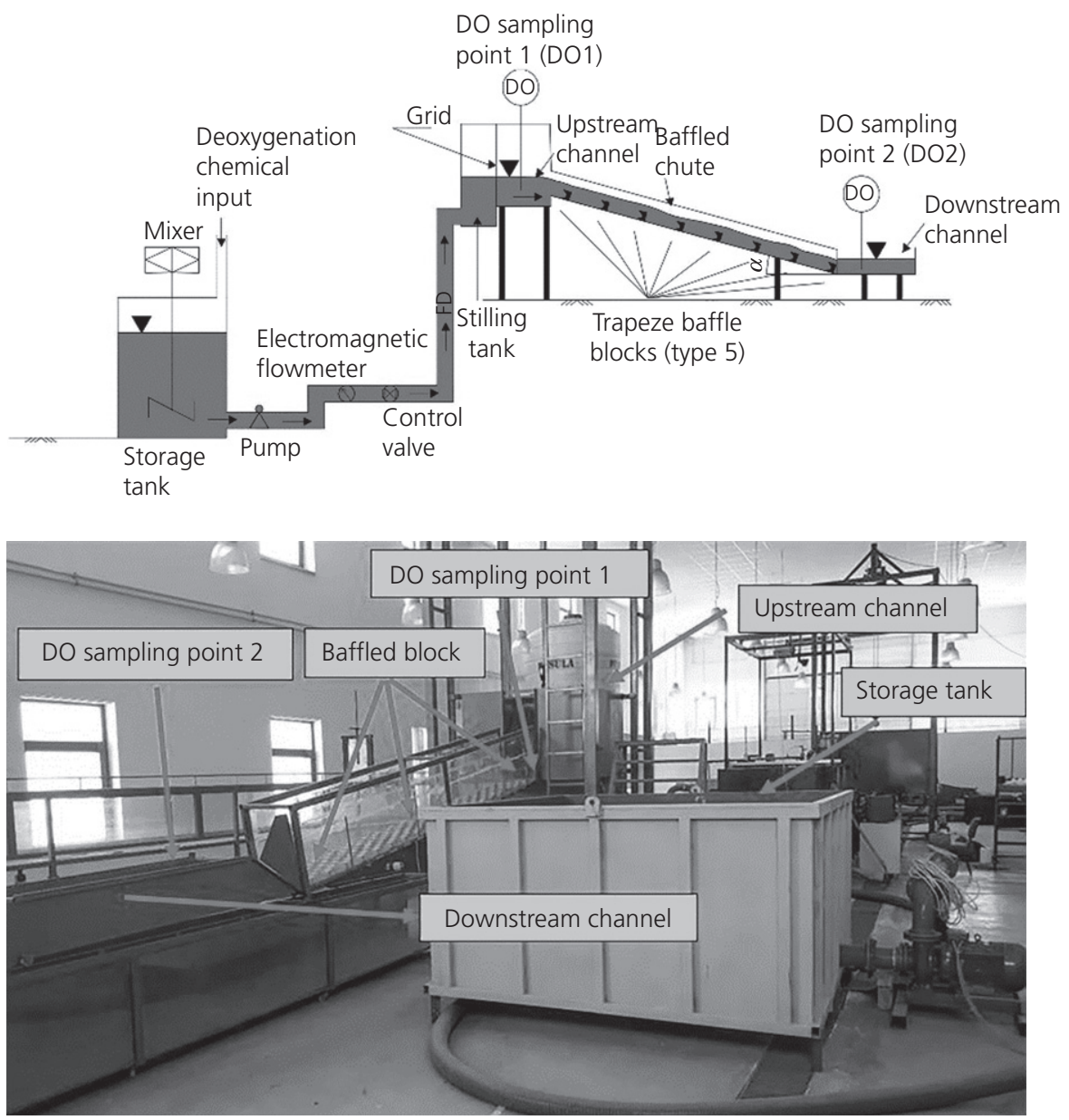

Figure 1. Image and schematic view of the experimental setup

damage. Figure 3 shows the row plan, pictures of the blocks and the arrangement of blocks in the channel. For engineering applications, some of these blocks could be produced from high-density polyethylene material. The blocks could be produced in factories according to their design shapes and could be mounted on the concrete of the chute with anchorages. In addition, different formwork methods could be used to produce concrete forms. Blocks similar to those used in the current study were used by Jangam et al. (2017), who suggested the concrete casting method used for the protection of coastal blocks, which is useful for engineering applications.

The specified block sizes were compatible with design guidelines of Peterka (1984). The baffled chute was designed based on the maximum flow rate $(Q)$ and the per unit flow $\left(q\right.$, in $\left.\mathrm{m}^{2} / \mathrm{s}\right)$ was computed from $q=Q / W\left(Q\left(\mathrm{~m}^{3} / \mathrm{s}\right)\right.$ being the flow rate in the channel and $W(\mathrm{~m})$ the inlet width of the baffled chute). After determining $q$, the critical depth $d_{\mathrm{c}}(\mathrm{m})\left(d_{\mathrm{c}}=\left(q^{2} / \boldsymbol{g}\right)^{1 / 3}\right)$ and critical velocity $V_{\mathrm{c}}(\mathrm{m} / \mathrm{s})\left(V_{\mathrm{c}}=\left(\boldsymbol{g} d_{\mathrm{c}}\right)^{1 / 2}\right)$ were calculated. According to Peterka (1984), the block height $(H)$ should be between $0.8 d_{\mathrm{c}}$ and $0.9 d_{\mathrm{c}}$. However, the block heights are flexible and can be changed provided that structural stability is maintained (Aisenbrey et al., 1978). The slope of the chute channel is recommended to be $2: 1$ (horizontal: vertical) or flatter. However, with the slope in decimal form along the channel length and the rows of blocks placed at staggered intervals, the distance of block rows must be equal to $H / S$ where $S$ is the slope of the chute channel. The baffle block widths and interstitial spaces were as recommended by Peterka (1984). There was no need to use a fragmented block because the block width was designed to be a multiple of the channel width. The block widths and horizontal distances between blocks are recommended to be $1.5 \mathrm{H}$, but not less than $H$. In the current work, the distance between rows of baffle blocks was taken as $H$. In addition, the training wall height should be at least three times the block height in order to prevent the flow overflowing and splashing out of the channel. In this experimental study, the baffled chute training walls were taken as $6 H$. Detailed plan representations of the blocks and their arrangement in the channel are shown in Figure 3.

In this study, a total of 252 tests were performed using the six different block types and the channel with no blocks. 

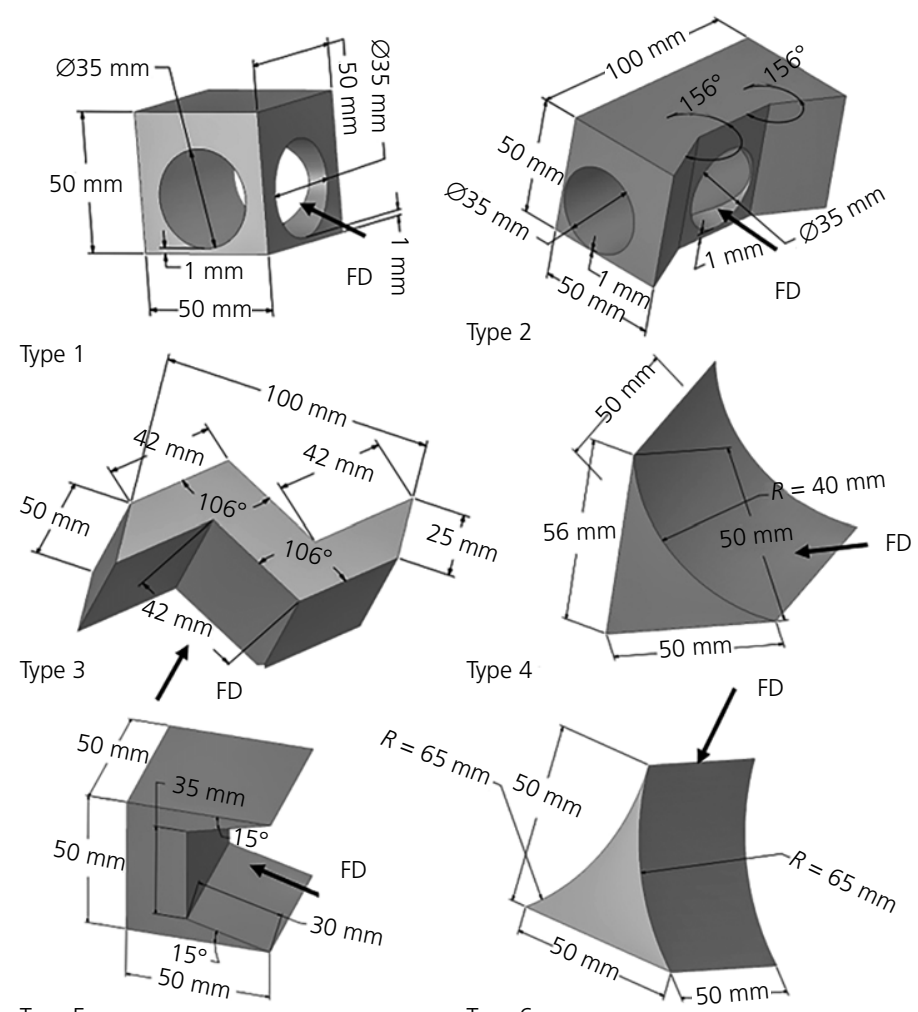

Type 5

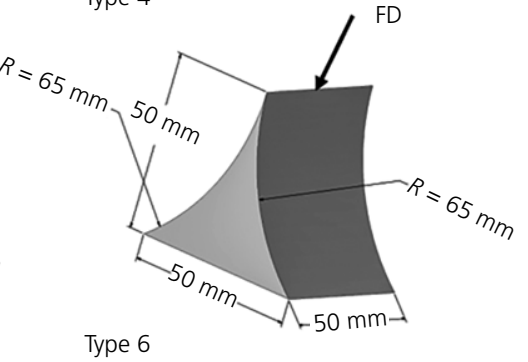

(a)

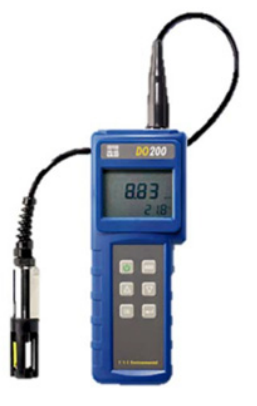

(b)

Figure 2. (a) Dimensions and geometry of the block types; (b) YSI DO200 oxygen meter

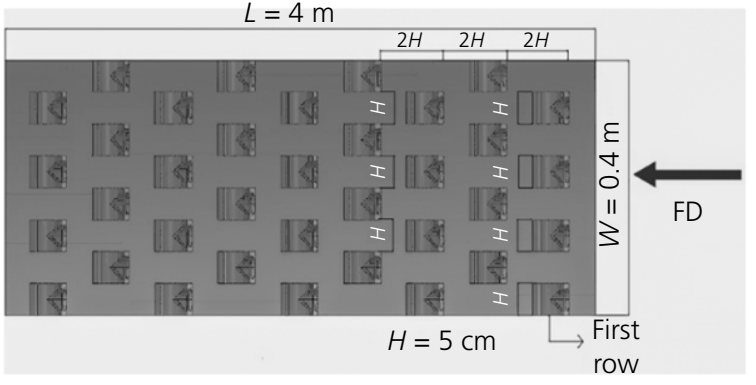

(a)

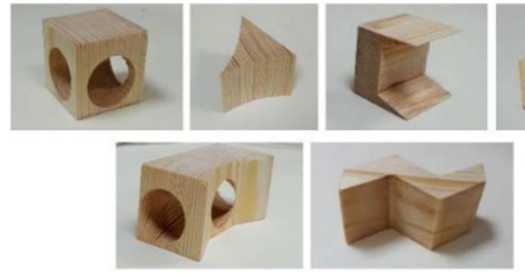

(b)

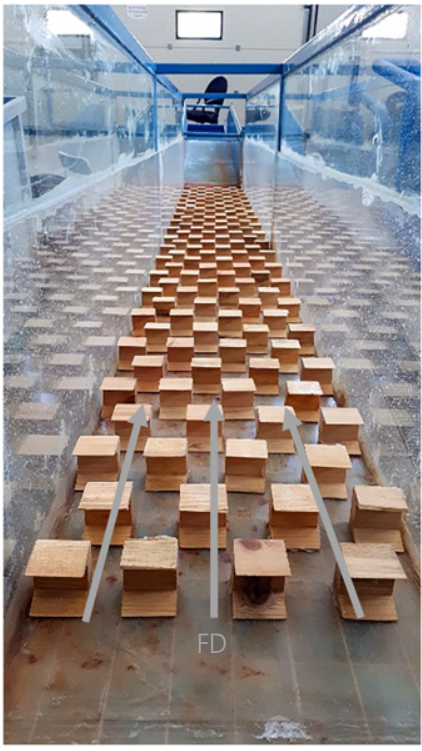

(c)

Figure 3. (a) Baffle blocks row plan; (b) Produced blocks; (c) Arrangement of blocks inside the channel

All experiments were performed at six different chute angles $\left(\alpha=10^{\circ}, 20^{\circ}, 30^{\circ}, 40^{\circ}, 50^{\circ}\right.$ and $\left.56^{\circ}\right)$. All of the experimental ranges are shown in Table 1. Regarding scale effects, minimum scale effects are reported by BaCaRa (1991) for $h \geq 0.028 \mathrm{~m}$, by Chanson (2009) for steps higher than $2 \mathrm{~cm}$ and $\operatorname{Re}>2.5 \times 10^{4}$ and by Kobus (1984) for $\operatorname{Re}>1 \times 10^{5}$. As 
Table 1. Summary of experiments

\begin{tabular}{|c|c|c|c|c|c|}
\hline Block type & Chute angle, $\alpha:^{\circ}$ & $q: \times 10^{-3} \mathrm{~m}^{2} / \mathrm{s}$ & Fr at chute inlet & Block height, $H: \mathrm{mm}$ & $\operatorname{Re} \times 10^{5}$ \\
\hline None & $10-56$ & $12.5-75$ & $0.64-0.98$ & - & $1.22-7.35$ \\
\hline Type 1 & $10-56$ & $12.5-75$ & $0.64-0.98$ & 50 & $1.22-7.35$ \\
\hline Type 2 & $10-56$ & $12.5-75$ & $0.64-0.98$ & 50 & $1.22-7.35$ \\
\hline Type 3 & $10-56$ & $12.5-75$ & $0.64-0.98$ & 50 & $1.22-7.35$ \\
\hline Type 4 & $10-56$ & $12.5-75$ & $0.64-0.98$ & 50 & $1.22-7.35$ \\
\hline Type 5 & $10-56$ & $12.5-75$ & $0.64-0.98$ & 50 & $1.22-7.35$ \\
\hline Type 6 & $10-56$ & $12.5-75$ & $0.64-0.98$ & 50 & $1.22-7.35$ \\
\hline
\end{tabular}

shown in Table 1, in this study Re was in the range $1.22 \times 10^{5}$ to $7.35 \times 10^{5}$, thus providing minimal scale effects.

The DO content parameter was measured using a DO meter with a measurement range of $0-20 \mathrm{ppm}, 0-200 \% \mathrm{DO} \%$ air saturation and temperature $-6^{\circ}$ to $46^{\circ} \mathrm{C}$. At the beginning of each test, sodium sulfite $\left(\mathrm{Na}_{2} \mathrm{SO}_{3}\right)$ and cobalt chloride $\left(\mathrm{CoCl}_{2}\right)$ were added to the storage tank and mixed for deoxygenation of the water. For each six measurements (for flow rates of 5,10 , 15, 20, 25 and $30 \mathrm{l} / \mathrm{s}$ ), the storage tank was filled with approximately $6 \mathrm{~m}^{3}$ of water in every round. A YSI DO200 oxygen meter was used in the tests (Figure 2(b)). Before usage of the oxygen meter, it was calibrated daily in humid air in accordance with the manufacturer's calibration process. After each measurement, the probe was shaken and any air bubbles adhering to it were removed. During the measurements, the adherence of air bubbles was prevented by moving the probe in the water slowly. In addition, saturation concentrations were determined in accordance with the chart given by McGhee (1991). Tap water was used in tests to eliminate the effect of salinity. During the tests, the water was continuously monitored to ensure that there was no substantial accumulation of residues caused by the

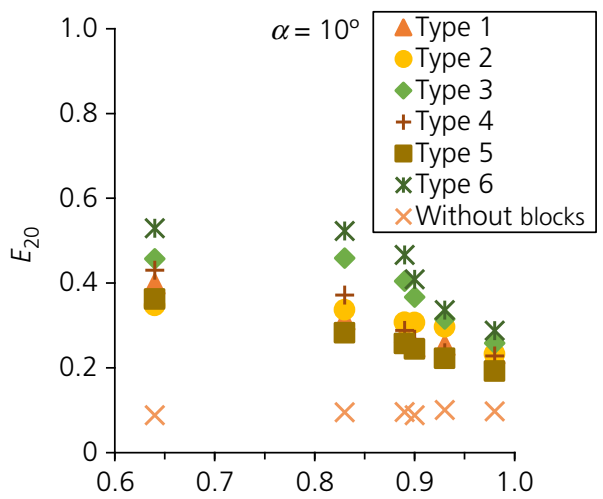

(a)

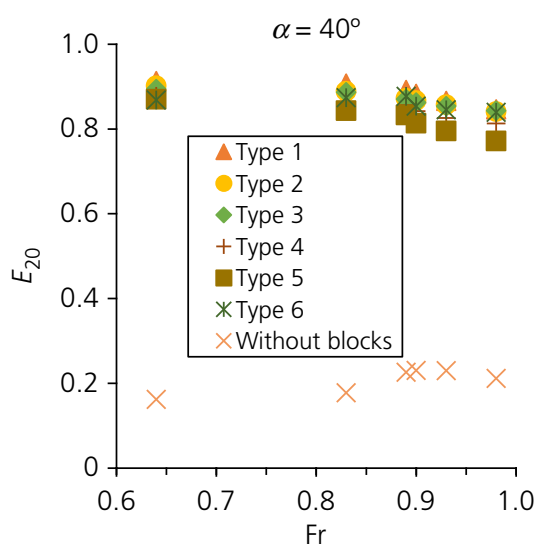

(d)

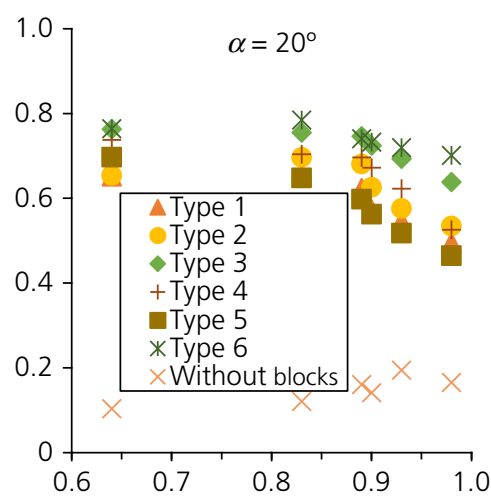

(b)

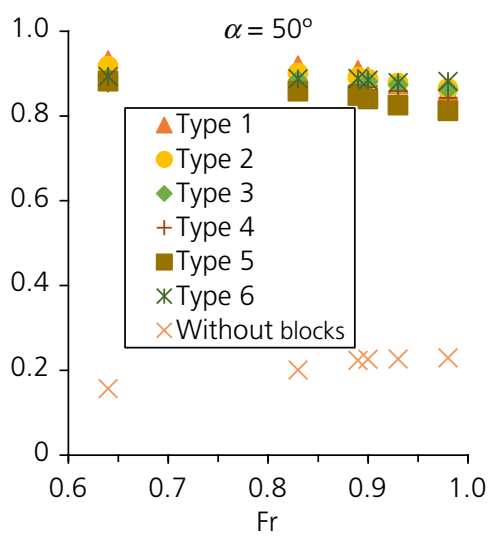

(e)

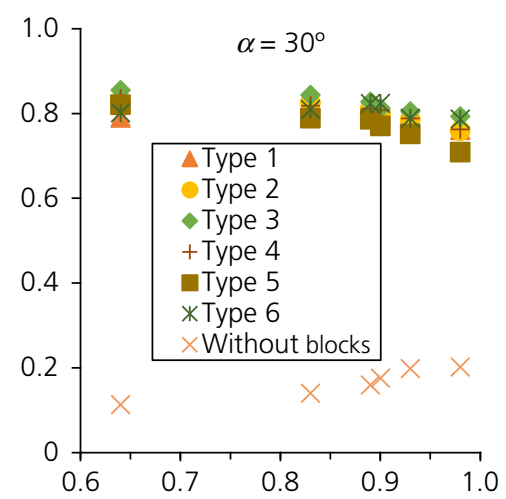

(c)

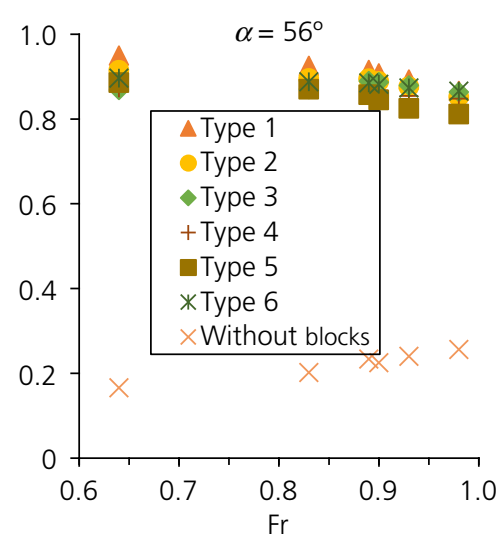

(f)

Figure 4. Variation of oxygen transfer efficiency with Froude number 
chemicals applied to the water for deoxygenation. Many tests were carried out to reduce the oxygen content of the water in the storage tank to about $0.5 \mathrm{mg} / \mathrm{l}$. The reaction times for the chemicals in water were determined from these tests. Theoretically, $7.9 \mathrm{~g} / \mathrm{m}^{3}$ of sodium sulfite is needed to eliminate $1 \mathrm{~g} / \mathrm{m}^{3}$ of DO. Based on the DO of the tap water used in the tests, the approximate sodium sulfite requirements were determined (10-20\% excess was used). Generally, the use of cobalt chloride as a catalyst for the deoxygenation reaction is needed at a dosage of $3.3 \mathrm{~g} / \mathrm{m}^{3}$. In this analysis, sodium sulfite was added at $50 \mathrm{~g} / \mathrm{m}^{3}$ and cobalt chloride at $3.3 \mathrm{~g} / \mathrm{m}^{3}$ (Baylar et al., 2006). During the measurements, the probe was immersed in the water for at least $1 \mathrm{~min}$ and then left. If the values on the oxygen meter did not vary, readings were taken. This process avoided measurement errors due to air bubbles attached to the sensor. All the data were obtained as instantaneous measurements.

As shown in Figure 1: DO sampling point 1 (DO1) was before the chute in the upstream channel and DO sampling point 2 (DO2) was $0.5 \mathrm{~m}$ beyond the end of the chute in the downstream channel. In the upstream flow, the velocity was low and the flow depth was about $0.20 \mathrm{~m}$. Oxygen measurements in DO1 were made at the top of a staircase. At DO2, the flow depth was less than at DO1. All the DO measurements were taken at least three times to provide confirmation of the measurements. Additionally, the flow had many bubbles in the chute but the bubbles decreased considerably within the downstream channel. Thus, measurements at DO2 were made very carefully in order not to be affected by the presence of bubbles. The locations of the DO sampling points were selected to demonstrate variation of the oxygen level of the water through the chute.

\section{Oxygen transfer efficiency results}

To compare the oxygen transfer efficiencies accurately, values of the dimensionless Froude number $(\mathrm{Fr})$ and $E_{20}$ were compared for different chute angles. The Froude number was calculated using mean velocity and depth values taken from the top of the chute. In other words, the inflow Froude number at the upstream weir crest was used. Figure 4 shows the variation of $E_{20}$ with $\mathrm{Fr}$ for the different chute angles: the oxygen transfer efficiency decreased with an increase in the Froude number. This result is compatible with other findings in the literature. The oxygen transfer efficiency decreased because contact of the water with the blocks was reduced with an amount of water passing rapidly through a certain channel. When water hits blocks, turbulent fluctuations occur and this increases the oxygen transfer efficiency. In this experimental study, aeration started at the beginning of the chute because of the geometric shapes of blocks. In other words, aeration occurred throughout the chute. The inception point of aeration from the crest was thus not measured.

Downstream of some hydraulic structures such as high dams, the total dissolved gas level can exceed the saturation level.
This can cause the death of fish. In this study, all the $E_{20}$ values were found to be below the supersaturation level $(<1)$, as shown in Figure 4. However, for the steep chute angles $\left(50^{\circ}\right.$ and $56^{\circ}$ ), $E_{20}$ for some block types (i.e. type 1 and type 2 ) was found to be near the supersaturation level. In general, baffled blocks are used in sloped irrigation channels. DO amounts near the supersaturation level may thus not cause a significant problem. However, engineers should bear this point in mind in the design stage of baffled chute channels.

As shown in Figures 4(a) and 4(b), the highest oxygen transfer efficiencies for chute angles of $10^{\circ}$ and $20^{\circ}$ were obtained for the type 6 block. It is thought that this type of block increased turbulence fluctuations (and thus increased oxygen transfer efficiency) by dividing the flow into two parts. For $\alpha=30^{\circ}$, the best oxygen transfer efficiency was achieved for the type 3 block. The oxygen transfer efficiency naturally increased due to the geometry of the block. The type 3 block causes many jumps on the surface, is hit by water and transmits the flow by dissipating it to the following block row. As shown in Figure 5, strong turbulent flow appeared in the chute; the streamlines through the chute are also shown in this figure.

For the greater chute angles $\left(\alpha=40^{\circ}, 50^{\circ}\right.$ and $\left.56^{\circ}\right)$, the highest efficiencies were obtained for the type 1 block (Figures 4(d)-4(f)). The internal shape of the type 1 block

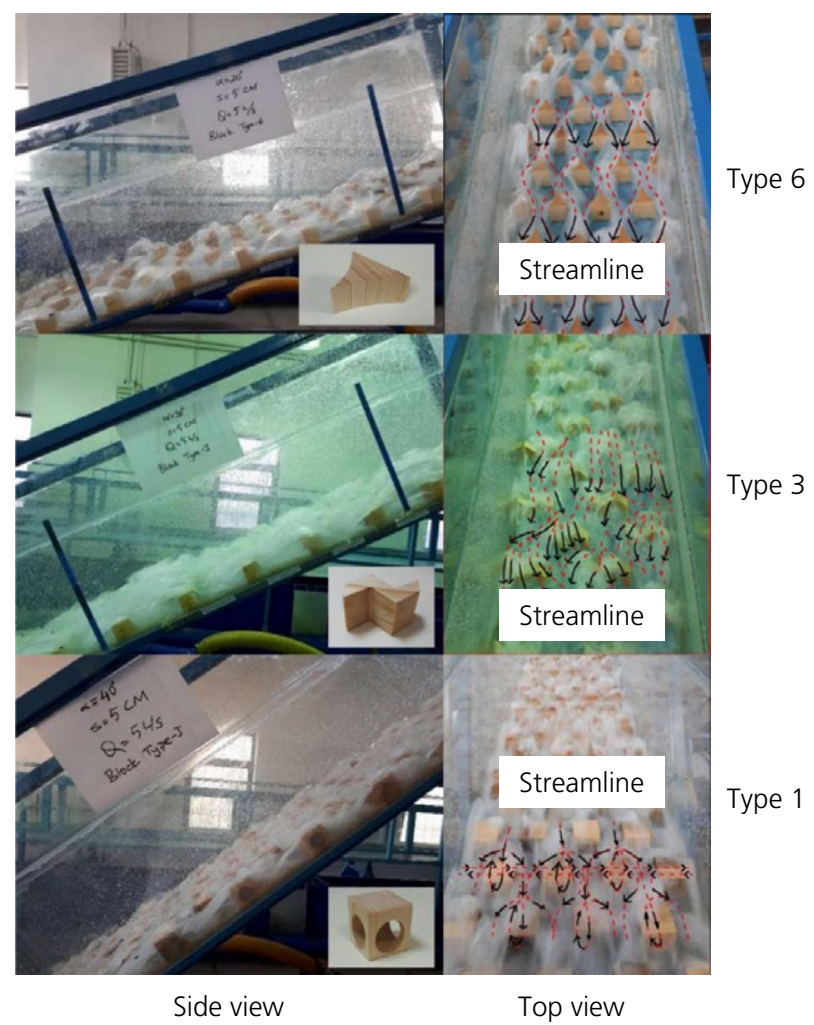

Figure 5. Views from experiments using type 6, type 3 and type 1 blocks 
(Figure 2(a)) allows water to enter into a narrow section. The water then divides into two parts and collides with the water coming from the adjacent block. The flow is transformed into a pressure pipe flow for a short time. This increases the interface area between the water and air, thus helping air bubbles to enter the flow.

All the block types affected oxygen transfer positively. The type 5 block provided the least oxygen transfer for all slopes except the $\alpha=10^{\circ}$ chute. Although this block has a trapezoidal section, the size of the surface area that the water comes into contact with perpendicular to the flow direction caused the current to jump too much and pass over the block easily. This block thus provided less oxygen transfer efficiency than the other blocks as it remained in a submerged position against the flow.

The oxygen transfer efficiency increased was found to increase with an increase in the channel slope. Increasing the slope increased the flow velocity, but the block geometry and unit discharge values were also important factors. All of these parameters affected the amount of air bubbles entering the water, with a subsequent increase in oxygen concentration. This is in good agreement with previous studies on stepped spillways
(Boes and Hager, 2003; Bung and Valero, 2016; Gonzalez and Chanson, 2008; Zhang and Chanson, 2018). In addition, an increase in channel length means an increase in the number of baffle blocks, which will also directly increase the oxygen transfer efficiency.

In order to determine the effect of the baffle blocks in more detail, the oxygen transfer efficiencies $\left(E_{20}\right)$ were compared in terms of the chute angle $(\alpha)$. These results are shown in Figures 6(a)-6(f). For the highest angle $\left(\alpha=56^{\circ}\right)$, the maximum oxygen transfer efficiency (approximately 95\%) was generally observed for the type 1 block. Compared with the other blocks, the type 1 block also provided the highest oxygen transfer efficiency at angles of $40^{\circ} \leq \alpha \leq 56^{\circ}$. For $\alpha=30^{\circ}$, the oxygen transfer efficiencies for all block types were very close to each other. Thus, in practice, any type of block that is easier to produce can be selected in this case. The highest increase rate in oxygen transfer efficiencies was obtained for $\alpha=20^{\circ}$. The block shapes did not have the same effects at different unit discharges $(q)$. Selection of the unit design discharge and the block type depending on the chute angle is this important in engineering applications. Figure 6 shows that, in the experiments without blocks, the oxygen transfer efficiencies increased with an increase in the chute slope.

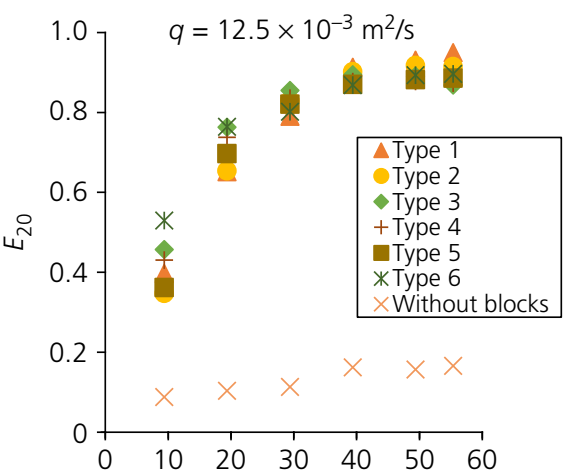

(a)

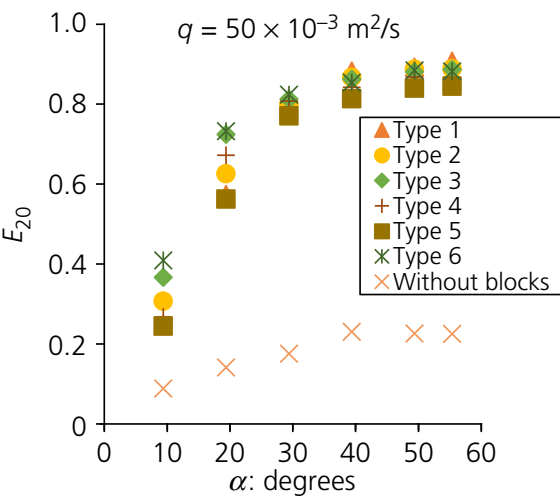

(d)

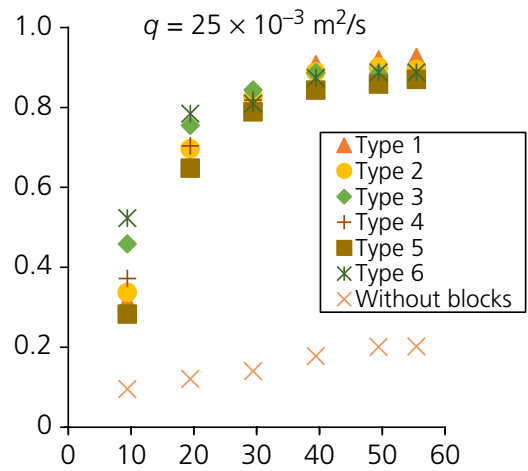

(b)

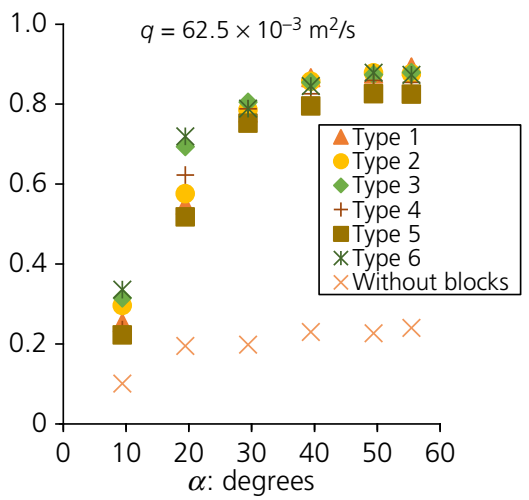

(e)

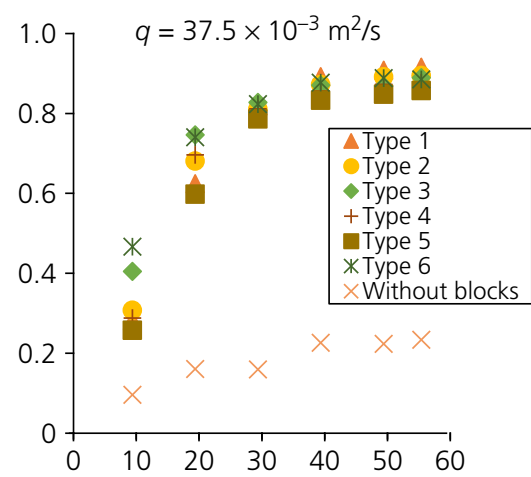

(c)

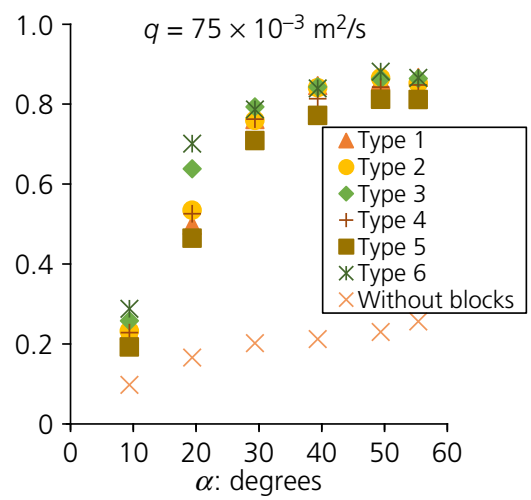

(f)

Figure 6. Chute angle relationship of oxygen transfer efficiency 
The reason for this is that the increased flow passing through the chute caused more turbulence and thus increased the amount of oxygen.

Flow images of experiments using type 2, type 4 and type 5 blocks are shown in Figure 7. As shown in the figure, the different block types formed different streamlines, thus creating different the turbulence and flow directions around the blocks. The results obtained in this study were compared with data from studies in the literature (Figure 8). In order to compare the present results with those reported in other studies, similar block heights were selected. For similar flow scenarios, similar chute angles were also selected.

For $\alpha=10^{\circ}$ (Figure 8(a)) the highest oxygen transfer efficiencies were obtained for $s=0.05 \mathrm{~m}$ from Baylar et al. (2006), where $s$ is step height and the type 6 block in this study. The oxygen transfer efficiencies for the other block types in the $10^{\circ}$ slope were better than the results reported by Baylar et al. (2006). These findings clarify that, using steps have low heights in very smooth slope channels provide more efficient oxygenation. When chute slope and step heights increase, oxygenation efficiency decreased otherwise effect of baffle blocks is increased.

For the $\alpha=30^{\circ}$ chute (Figure 8(b)), all the block types used in the present study provided better oxygen efficiencies than the

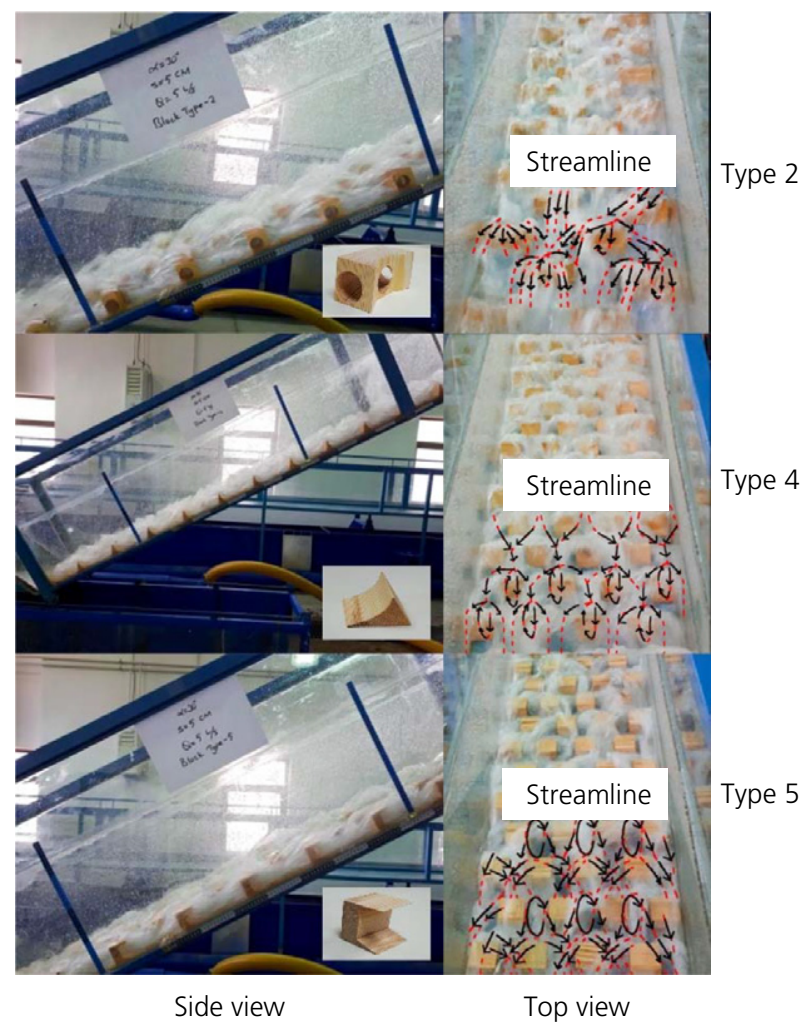

Figure 7. Views from experiments using type 2, type 4 and type 5 blocks literature results, but especially block types 1, 3, 4 and 6. The results from the current study and the results of Kaya and Emiroglu (2010) were close, despite the use of different block types. In engineering applications, it is very important to select the most economic and efficient type of hydraulic structure. Decisions about which structure should be chosen for the same slope can be made by examining the oxygen transfer efficiency, step and block heights and the cost of fabricating the block geometry.

For $\alpha=40^{\circ}$ and $\alpha=50^{\circ}$, the results of this study were compared with the results reported by Tebbutt (1972) and Kaya and Emiroglu (2010) (Figures 8(c) and 8(d)). The $E_{20}$ values obtained in the current study were all higher than the literature values for both chute angles. The chute widths were $0.40 \mathrm{~m}$ in the present study and $0.30 \mathrm{~m}$ in the study of Kaya and Emiroglu (2010). The number of blocks in the chute in this work was thus greater than in the experiments conducted by Kaya and Emiroglu (2010), which could be a reason for the higher $E_{20}$ values. On the other hand, the study of Tebbutt (1972) was conducted in a stepped cascade. The reason for the higher results of this study can be explained according to description given above. In the experiments, the blocks used in this study provided strong turbulence and aeration effects, which explains the higher oxygen transfer efficiencies obtained.

\section{Conclusions}

In this experimental study, the oxygen efficiencies of six different block types were tested. Experiments were also performed in the chute without blocks.

Compared to the chute without any blocks, all types of blocks considered significantly increased the oxygen transfer efficiency all chute angles and unit flows. No type of block showed the same effect as the others at different chute angles. The type 1 block provided greater oxygen transfer efficiency at high angles while the type 6 block provided greater oxygen transfer efficiency for lower slopes.

The block geometry had a clear effect on the oxygen transfer efficiency $\left(E_{20}\right)$. More complex blocks, greater turbulence and a more chaotic medium provided higher $E_{20}$ values. The oxygen transfer efficiency of the baffled chute was found to be greater than that for a stepped spillway.

The highest oxygen transfer efficiencies were obtained at the greatest highest chute angle $\left(\alpha=56^{\circ}\right)$. The type 1 block showed the best results at this angle. The oxygen transfer efficiency increased with an increase in the chute angle, but it decreased with an increase in the Froude number (Figure 4).

The tests were carried out in an open channel. Large-scale flume designs are difficult to design without scale effects due to their high turbulence and flow velocities. The scale effect in this study was the minimum. At the same time, this study is 


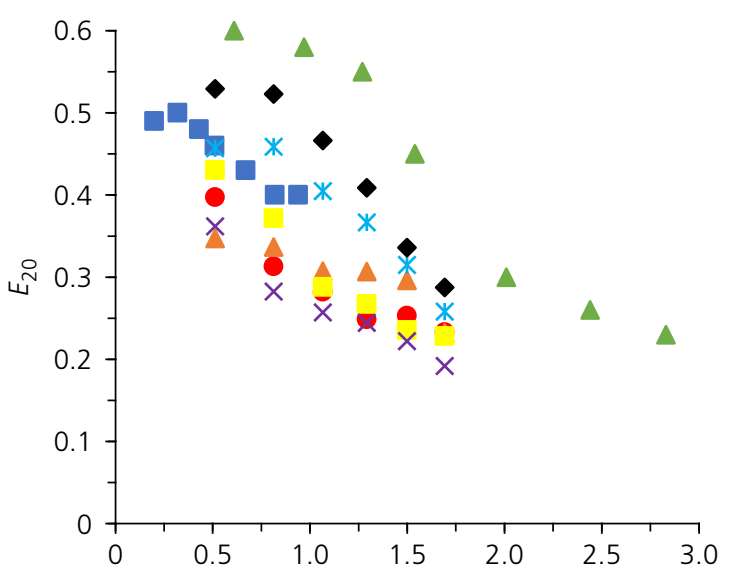

(a)
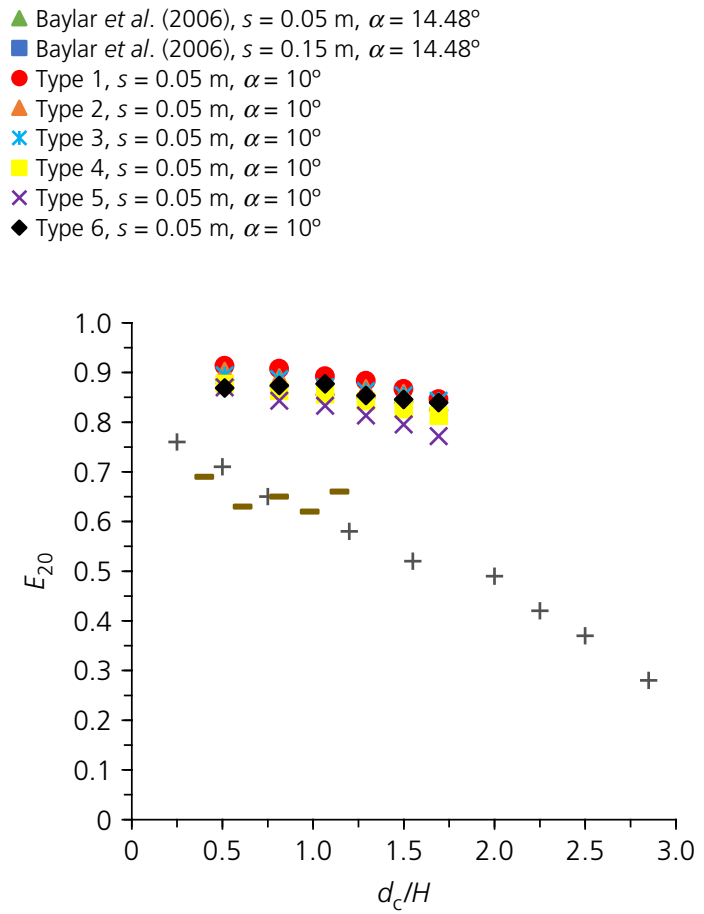

(c)

+ Tebbut (1972), $s=0.073 \mathrm{~m}, \alpha=45^{\circ}$

- Kaya and Emiroglu (2010), $s=0.08 \mathrm{~m}, \alpha=42.54^{\circ}$

Type $1, s=0.05 \mathrm{~m}, \alpha=40^{\circ}$

Type $2, s=0.05 \mathrm{~m}, \alpha=40^{\circ}$

* Type $3, s=0.05 \mathrm{~m}, \alpha=40^{\circ}$

Type $4, \mathrm{~s}=0.05 \mathrm{~m}, \alpha=40^{\circ}$

$\times$ Type $5, \mathrm{~s}=0.05 \mathrm{~m}, \alpha=40^{\circ}$

- Type $6, s=0.05 \mathrm{~m}, \alpha=40^{\circ}$

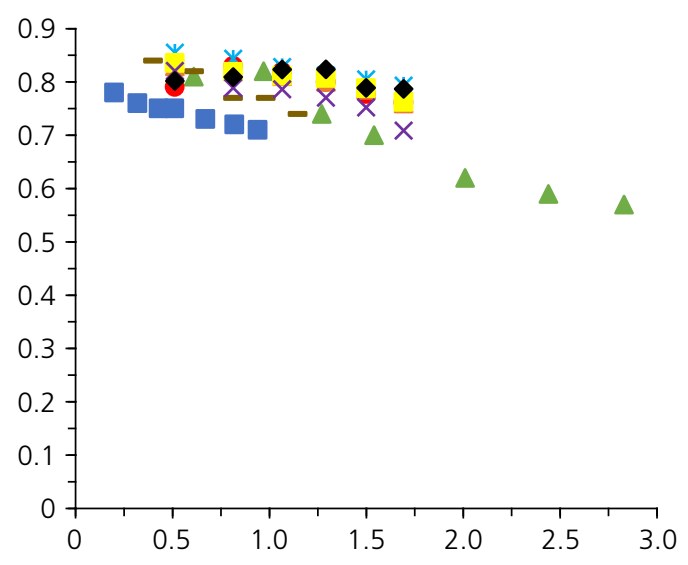

(b)

$\triangle$ Baylar et al. (2006), $s=0.05 \mathrm{~m}, \alpha=30^{\circ}$

- Baylar et al. (2006), $s=0.15 \mathrm{~m}, \alpha=30^{\circ}$

- Kaya and Emiroglu (2010), $s=0.08 \mathrm{~m}, \alpha=31.74^{\circ}$

- Type $1, s=0.05 \mathrm{~m}, \alpha=30^{\circ}$

Type 2, $s=0.05 \mathrm{~m}, \alpha=30^{\circ}$

* Type 3, $s=0.05 \mathrm{~m}, \alpha=30^{\circ}$

Type $4, s=0.05 \mathrm{~m}, \alpha=30^{\circ}$

$\times$ Type $5, s=0.05 \mathrm{~m}, \alpha=30^{\circ}$

- Type $6, s=0.05 \mathrm{~m}, \alpha=30^{\circ}$

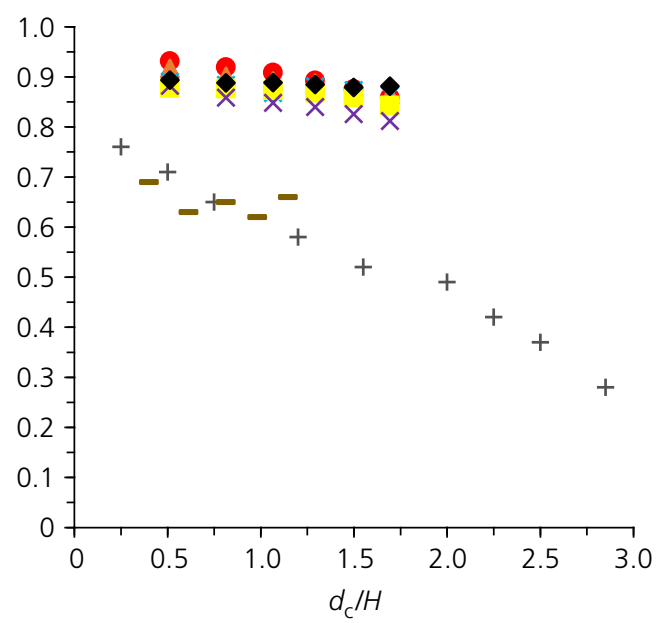

(d)

+ Tebbut (1972), $s=0.073 \mathrm{~m}, \alpha=45^{\circ}$

- Kaya and Emiroglu (2010), $s=0.08 \mathrm{~m}, \alpha=42.54^{\circ}$

- Type $1, s=0.05 \mathrm{~m}, \alpha=50^{\circ}$

$\triangle$ Type 2, $s=0.05 \mathrm{~m}, \alpha=50^{\circ}$

* Type $3, s=0.05 \mathrm{~m}, \alpha=50^{\circ}$

Type $4, s=0.05 \mathrm{~m}, \alpha=50^{\circ}$

$\times$ Type $5, \mathrm{~s}=0.05 \mathrm{~m}, \alpha=50^{\circ}$

- Type $6, \mathrm{~s}=0.05 \mathrm{~m}, \alpha=50^{\circ}$

Figure 8. Comparison of the results from this study and others in the literature for chute angles of: (a) $20^{\circ}$; (b) $30^{\circ}$; (c) $40^{\circ}$; (d) $50^{\circ}$

compatible with studies with a maximum design flow of $75 \times 10^{-3} \mathrm{~m}^{2} / \mathrm{s}$ and the block design criteria of Peterka (1984).

The blocks used in this study provided very similar oxygen transfer efficiencies for higher slopes $\left(\alpha>40^{\circ}\right)$. Depending on the geometric shapes of the blocks, the angle of the chute channel is a very important consideration for the most economical design and use in practice. According to this experimental study, the type 6 block is appropriate for chute slopes of $10^{\circ}-20^{\circ}$, the type 3 block is appropriate for chute slopes of $30^{\circ}$ and the type 1 block is appropriate for chute slopes $>40^{\circ}$. 
The tests showed that baffled chutes have very good oxygen transfer performance, especially in terms of the oxygen transfer efficiency. Thus, when selecting the type of spillway chute or stilling basin, it may be possible to use appropriate blocks to provide both oxygen transfer and energy dissipation.

Although all the $E_{20}$ values were found to be below the supersaturation level $\left(E_{20}<1\right)$ in this study, some of the $E_{20}$ values, especially for the steep chute angles of $50^{\circ}$ and $56^{\circ}$, were near the supersaturation level. Thus, in applications, engineers should pay attention to protecting aquatic life from harm due to over-oxygenation of water.

\section{Data availability}

Some or all of the data, models or code that support the findings of this study are available from the corresponding author upon reasonable request.

\section{Acknowledgement}

This paper has been produced from M. Aydoğdu's $\mathrm{PhD}$ thesis (Aydoğdu, 2021). The research was supported by the Research Fund of the Inonu University Scientific Research Projects Unit (project IDs FDK-2018-1394, FBG-2018-1474 and FCD2018-1324).

\section{REFERENCES}

Aisenbrey AJ, Hayes R and Warren H (1978) Design of Small Canal Structures. United States Government Printing Office, Denver, CO, USA.

Ashour MA, Sayed T and El-Attar S (2014) A new water energy dissipater for efficient energy dissipation and enriching the flow with dissolved oxygen content. Limnological Review 14(1): 3-11, https://doi.org/10.2478/limre-2014-0001.

Aydoğdu M (2021) Investigation of the Energy Dissipation and Aeration Effect of Different Types of Baffle Blocks in Free Surface Flows. $\mathrm{PhD}$ thesis, The University of Inonu, Malatya, Turkey.

BaCaRa (1991) Etude de la Dissipation D'Energie sur les Evacuateurs à Marches. Rapport D'Essais. CEMAGREF-SCP, Aix-en-Provence, France (in French).

Baylar A and Emiroglu ME (2004) An experimental study of air entrainment and oxygen transfer at a water jet from a nozzle with air holes. Water Environment Research 76(3): 231-237, https://doi.org/10.2175/106143004x141780.

Baylar A, Emiroglu ME and Bagatur T (2006) An experimental investigation of aeration performance in stepped spillways. Water and Environment Journal 20(1): 35-42, https://doi.org/10.1111/ j.1747-6593.2005.00009.x.

Baylar A, Unsal M and Ozkan F (2010) Hydraulic structures in water aeration processes. Water, Air, and Soil Pollution 210(1-4): 87-100, https://doi.org/10.1007/s11270-009-0226-2.

Boes RM and Hager WH (2003) Hydraulic design of stepped spillways. Journal of Hydraulic Engineering 129(9): 671-679.

Bung D and Schlenkhoff A (2010) Self-aerated skimming flow on embankment stepped spillways: the effect of additional microroughness on energy dissipation and oxygen transfer. In Proceedings of the 1st IAHR European Congress, Edinburgh, UK, p. 6.

Bung DB and Valero D (2016) Optical flow estimation in aerated flows. Journal of Hydraulic Research 54(5): 575-580, https://doi.org/ 10.1080/00221686.2016.1173600.
Chanson H (2009) Turbulent air-water flows in hydraulic structures: dynamic similarity and scale effects. Environmental Fluid Mechanics 9(2): 125-142.

Chu K, Hua Z and Ji L (2014) Aeration at overflow dams with curved surfaces by different flashboard spillways. Journal of Environmental Engineering and Landscape Management 22(3): 226-236.

Essery ITS, Tebbutt THY and Rasaratnam SK (1978) Design of Spillways for Re-Aeration of Polluted Waters. Construction Industry Research and Information Association, London, UK.

Felder S and Chanson H (2009) Energy dissipation, flow resistance and gas-liquid interfacial area in skimming flows on moderate-slope stepped spillways. Environmental Fluid Mechanics 9(4): 427-441, https://doi.org/10.1007/s10652-009-9130-y.

Felder S, Geuzaine M, Dewals B and Erpicum S (2019) Nappe flows on a stepped chute with prototype-scale steps height: observations of flow patterns, air-water flow properties, energy dissipation and dissolved oxygen. Journal of Hydro-environment Research 27(4): 1-19, https://doi.org/10.1016/j.jher.2019.07.004.

Gameson ALH (1957) Weirs and the aeration of rivers. Journal of the Institution of Water Engineers 11: 477-490.

Gameson ALH, Vandyke KG and Ogden CG (1958) The effect of temperature on aeration at weirs. Water and Water Engineering 753(62): 489.

Gerger R, Kisi O, Faruk Dursun O and Emin Emiroglu M (2017) Applicability of several soft computing approaches in modeling oxygen transfer efficiency at baffled chutes. Journal of Irrigation and Drainage Engineering 143(5): 1-11, https://doi.org/10.1061/ (ASCE)IR.1943-4774.0001153.

Gonzalez CA and Chanson H (2008) Turbulence manipulation in air-water flows on a stepped chute: an experimental study. European Journal of Mechanics B/Fluids 27(4): 388-408, https:// doi.org/10.1016/j.euromechflu.2007.09.003.

Gulliver JS and Rindels AJ (1993) Measurement of air-water oxygen transfer at hydraulic structures. Journal of Hydraulic Engineering 119(3): 327-349.

Gulliver JS, Thene JR and Rindels AJ (1990) Indexing gas transfer in self-aerated flows. Journal of Environmental Engineering 116(3): 503-523.

Gulliver JS, Hibbs DE and McDonald JP (1997) Measurement of effective saturation concentration for gas transfer. Journal of Hydraulic Engineering 123(2): 86-97.

Gulliver JS, Wilhelms SC and Parkhill KL (1998) Predictive capabilities in oxygen transfer at hydraulic structures. Journal of Hydraulic Engineering 124(7): 664-671.

Jangam P, Kudave S, Kadage V, Waghmare N and Malu M (2017) To study the science behind the construction and techniques of Burj Al Arab. International Journal of Engineering Technology Science and Research 4(4): 309-315.

Kaya N and Emiroglu ME (2010) Study of oxygen transfer efficiency at baffled chutes. Proceedings of the Institution of Civil Engineers Water Management 163(9): 447-456, https://doi.org/10.1680/wama. 900029.

Kherbache K, Chesneau X, Zeghmati B, Abide S and Benmamar S (2017) The effects of step inclination and air injection on the water flow in a stepped spillway: a numerical study. Journal of Hydrodynamics 29(2): 322-331, https://doi.org/10.1016/S1001-6058(16)60742-4.

Kobus H (1984) Scale effects in modelling hydraulic structures. Proceedings of International Symposium on Scale Effects in Modelling Hydraulic Structures, Esslingen, Germany. IAHR, Esslingen, Germany.

Kobus H (1991) Introduction to air-water flows. In Air Entrainment in Free-Surface Flows. IAHR Hydraulic Structures Design Manuals 4 (Wood IR (ed.)). Routledge, London, UK, pp. 1-28.

Küçükali S and Çokgör Ş (2011) Examination of the aeration efficiency of the hydraulic jump. ITU Journal -Engineering 5(5): 56-66. 
Luna-Bahena JC, Pozos-Estrada O, Ortiz-Martinez VM and Gracia-Sanchez J (2018) Experimental investigation of artificial aeration on a smooth spillway with a crest pier. Water 10(10): 1383, https://doi.org/10.3390/w10101383.

Markofsky M and Kobus H (1978) Unified presentation of weir-aeration data. Journal of the Hydraulic Division 104(4): 562-568.

McGhee TJ (1991) Water Supply and Sewerage. McGraw-Hill, New York, NY, USA.

Medhi BJ, Singh A, Thokchom AK and Mahapatra S (2019) Experimental and computational study on flow over stepped spillway. Journal of Mechanical Science and Technology 33(5): 2101-2112, https:// doi.org/10.1007/s12206-019-0116-5.

Peterka AJ (1984) Hydraulic Design of Stilling Basins and Energy Dissipators. United States Department of the Interior United States Bureau of Reclamation, Denver, CO, USA.

Qu L, Li R, Li J, Li K and Deng Y (2011) Field observation of total dissolved gas supersaturation of high-dams. Science China Technological Sciences 54(1): 156-162.

Raikar RV and Kamatagi PB (2015) Use of hydraulic phenomena in enhancement of dissolved oxygen concentration. International Journal of Research in Engineering and Technology 4(2): 568-574.

Tebbutt THY (1972) Some studies on reaeration in cascades. Water Research 6(3): 297-304, https://doi.org/10.1016/0043-1354(72) 90007-3.

Terrier S, Pfister M and Schleiss AJ (2016) Effect of a deflector aerator on stepped spillway flow. In Proceedings of the 6th International Symposium on Hydraulic Structures: Hydraulic Structures and Water System Management, ISHS 2016 (Crookston B and Tullis B (eds)), pp. 151-160, https://doi.org/10.15142/T330628160857.

Toombes L and Chanson H (2005) Air-water mass transfer on a stepped waterway. Journal of Environmental Engineering 131(10): 1377-1386, https://doi.org/10.1061/(ASCE)0733-9372 (2005)131:10(1377).
Wang J and Zhang Z (2020) Phytoplankton, dissolved oxygen and nutrient patterns along a eutrophic river-estuary continuum: Observation and modeling. Journal of Environmental Management 261: 110233.

Wang J, Zhang Z and Johnson B (2019) Low flows and downstream decline in phytoplankton contribute to impaired water quality in the lower Minnesota River. Water Research 161: 262-273.

Wang J, Bombardelli FA and Dong X (2021) Physically based scaling models to predict gas transfer velocity in streams and rivers. Water Resources Research 57(3): e2020WR028757.

Watson CC, Walters RW and Hogan SA (1998) Aeration performance of low drop weirs. Journal of Hydraulic Engineering 124(1): 65-71.

Wood IR (ed.) (1991) Air Entrainment in Free-Surface Flows. IAHR Hydraulic Structures Design Manuals 4. Routledge, London, UK.

Wu JH, Zhang B and Ma F (2013) Inception point of air entrainment over stepped spillways. Journal of Hydrodynamics 25(1): 91-96, https://doi.org/10.1016/S1001-6058(13)60342-X.

Wuthrich D and Chanson H (2015) Aeration performances of a gabion stepped weir with and without capping. Environmental Fluid Mechanics 15(4): 711-730, https://doi.org/10.1007/s10652-0149377-9.

Zhang G (2017) Free-Surface Aeration, Turbulence, and Energy Dissipation on Stepped Chutes with Triangular Steps, Chamfered Steps, and Partially Blocked Step Cavities. PhD thesis, The University of Queensland, Brisbane, Australia, https://doi.org/ 10.14264/uql.2017.906.

Zhang G and Chanson H (2017) Self-aeration in the rapidly- and gradually-varying flow regions of steep smooth and stepped spillways. Environmental Fluid Mechanics 17(1): 27-46, https://doi.org/10.1007/s10652-015-9442-z.

Zhang G and Chanson H (2018) Air-water flow properties in stepped chutes with modified step and cavity geometries. International Journal of Multiphase Flow 99: 423-436, https://doi.org/10.1016/ j.ijmultiphaseflow.2017.11.009.

\section{How can you contribute?}

To discuss this paper, please email up to 500 words to the editor at journals@ice.org.uk. Your contribution will be forwarded to the author(s) for a reply and, if considered appropriate by the editorial board, it will be published as discussion in a future issue of the journal.

Proceedings journals rely entirely on contributions from the civil engineering profession (and allied disciplines). Information about how to submit your paper online is available at www.icevirtuallibrary.com/page/authors, where you will also find detailed author guidelines. 